\title{
Perception and ICTs
}

\author{
http://dx.doi.org/10.3991/ijep.v5i3.4015 \\ Athanasios S. Drigas and Diatsigkos Dimitrios \\ NCSR DEMOKRITOS, Institute of Informatics and Telecommunications, Net Media Lab, Athens, Greece
}

\begin{abstract}
Perception as a thought process and as one of the most fundamental cognitive functions is considered as an important scientific field of study and therefore has been discussed intensively. The role of ICTs in brain perception is reviewed here. The importance of ICTs in children with special needs and perception difficulties is explored while the effectiveness of new technology in reading perceptual ability is presented. For the scope of our research, a comprehensive review of the most representative studies of the last decade was conducted with respect to the aforementioned aspects in order to survey the findings.
\end{abstract}

Index Terms-ICT, perception, language disorders, speech disorders, assessment, intervention.

\section{INTRODUCTION}

Perception is a process by which individuals identify, organize and interpret input to produce a meaningful experience of the environment. Our brain and especially our visual system are constantly overloaded. Computerized task rules are distinguished between the followings items: A) Size B) Intensity C) Frequency D) Status and Contrast of stimulus. A successful cognition assessment with enhanced tasks can contribute to brain performance, taking various training benefits into account [1]. Apparently, participants who trained the longest, improved the most [2]. The related literature also points out that individuals with different expectations and beliefs can perceive the same objects and events in very different ways. The allocation of the perceptional resources in visual tasks has been studied extensively. To make this discrimination, it was necessary to identify the ecological and the constructivist views of perception. Firstly, perception includes efferent information, as it is found in stimulus (ecological approach to perception) [3]. Secondly, perception "goes beyond the information given (constructivist view).

Considering the distribution of research, the visual world can be broken down into two broad categories. First, the perception of the substantial or spatial world and second, the perception of the world of useful and significant things to which we usually attend. The first category includes the sub-set of colors, textures, surfaces, edges, shapes and slopes. The second category includes the world with which we are usually concerned (object, places, people, signals and written symbols). The latter is characterized by an easier shifting from time to time, whereas the former remains more constant for our experience and may play a role in the decision to carry out an activity for moving about. In those circumstances, we do not perceive all the significant stimuli at once. This personal filtering is defined as selective perception. A particular type of features makes our selection distinctive in terms of the ongoing brain process compared to other neglected features. As a result of that, perception sometimes seems to be distorted and irreversible through this situation. Based on the aforementioned aspects, the term perception can be divided into two types, the first one being the literal and the second one the schematic type.

Taking into consideration these specific areas that are underlined above, our scoping study has considered national and international publications as well as the research and experimental findings of the last decade which focus on the use of ICT as an assessment tool concerning the three most important domains of perception: the perception process by dissection, perception and special needs, as well as reading perceptual ability. In addition, the various tests of perception such as n-back, illusions and simulation tests, have become representative examples of the knowledge acquired through this study, whereas before six different approaches of perception have been discussed over the past century. Finally, in that respect the questions which concern us most of all are, firstly : which are the types of perceptual phenomena that we use to form conjunctions with special needs and, secondly, what are the causes of these interesting phenomena? The resulting studies indicate that, for the purpose of tests, participants are related to mind procedures such as verbal or visual processing strategies as well as their combination

\section{Perceptual Process By Dissection}

The overall objective is to manage this varied so-called immediate process, and its brief description. Even though these methods have been extensively applied by many researchers, their basic characteristics are few in number. A brief exposure of displays followed by a distinguished number of ambiguous stimuli has thereby been employed. The results of such monitoring experiments are so many that only a small part of them can be considered. The experiments in these categories are grouped either on the basis of similar techniques or based on the general principles applicable to perception:

a. Linear perspectives [4]. In case we have well organized models in virtual environments the process of perception is more or less automated. [5]

b. The clearly perceived size or shape of an object [6]. Thus, on the basis of perception and beliefs we take action with respect to the object and modify the information provided by the object [7].

c. The fact of the relative apparent motion of objects - as the observer moves, or just his head or eyes move - through an otherwise stationary environment [8],[9]. Researchers refer to it as motion parallax effect [10].

d. The interposition of one object on another. Here, the placement of one thing between other things can make objects that are farther away less visible or unclear. Researchers suggest that the completeness of objects is a sign for distance [11]. The ob- 
PAPER

PERCEPTION AND ICTS

ject that is more complete and has regular outline tends to be the closest one.

e. The change in color as a 'distinct feature' can be used effectively in distance perception. Color variations like hue or saturation interpret 2D images in $3 \mathrm{D}$, but their compatibility effects of observation in depth and background are less accurate [12].

f. The rate through which the angular speed and size, or both of them, change an object in the visual field, provides information which is as important as the similar stimulus manipulations (e.g. background, depth) [13].

g. The relative brightness of objects. Research has shown that (sometimes in a mistaken manner), to the same extent as the distance from us increases in an ordinary environment, the intensity of its retinal image becomes lower [14]. This idea occurs to us only with reference to point sources, this principle does, however, on the contrary, not apply to reflecting surfaces [15].

h. The correlation between the lit area of an object and its shadow (contrast sensitivity) has been conceived to be a depth indicator [16].

i. The influence of the binocular disparities as discriminative stimulus to their depth analysis [17]. Variations in texture, size and in binocular disparity have been described extensively. Another source of perception information that renders perception cues even with a single eye has been mentioned by researchers as retinal blur phenomenon [18].

j. The convergence is the angle fixated by our eyes and the observed object. The closer the observed object is, the higher degrees of convergence we have [19].

\section{Perception AND SPECIAL NeEdS}

As was mentioned above, this paper seeks to uncover and explore what improvements have been made in tasks with static patterns associated with ICTs and special needs. To pursue that route we have focused on understanding some of the very latest research studies on each perceptual skill. The latter concern single features or other stimuli like brightness, colors, shape, object and forms.

In the last few years there has been a tendency among authors to describe primarily what first happened on the retina and afterwards they have provided explanations including later stages in the physiological process of seeing. Although not all results are consistent with each other, especially in relation to the hierarchy of variants, many sources have repeatedly determined where these factions are represented in the brain. For instance, research estimates that V1-V3 neurons have responses correlated with brightness stimulus in all conditions [20]. It should be mentioned that these conditions encompass a stimulus in which brightness modulation affects the perception of the adjoining or overlapping surfaces. The former area involves studies of how individuals with learning disabilities, autism or mental disorders react to static stimuli [21],[22]. The latter were assessed by using static information that varied in the complexity of the aforementioned conditions.
Moving up the visual pathway, we examined color as the next logical aspect of perception. It has been observed in the past that participation of different coloring in the same texture leads to object discrimination including faces [23],[24]. The physiological studies of face recognition suggest that discrete inferior regions of the extrastriate visual cortex, whose locations vary between individuals, are specialized for the recognition of faces [25]. In addition, the study of subjects with autism has revealed a reduced visual accuracy in the perception of colors [26]. Similar approaches are also important in studying clinical groups such as children with dyslexia who are impaired in tasks with static pattern recognition skills [27]. In the same wavelength, both background luminosity ratio and colors of on-screen text have been extensively considered to be related to dyslexia [28].

Among the factors considered by researchers, shape plays a special role in the field of perception. Shape as a logical aspect, derives from a step-by-step process beginning from the higher brain areas that gradually address the modulation of lower brain areas [29]. On the other hand, a bottom-up process comes from exogenous stimuli and proceeds through perceptual analysis without encompassing feedback information [30]. One approach of current research is to utilize the coexistence of bottom-up and topdown processes. The latter process occurs in illusions, and has long been recognized as a value in explaining brain mechanisms. The interest is heightened within the autistic spectrum. Autistic persons seem to have an almost better susceptibility to shape perception in comparison to typical individuals in low-level processes, although a mapping of high-level perceptual processes has revealed a lower degree of integration in them [31].

According to this mode, the perception of objects and forms has been mentioned as a process which activates specific aspects of the temporal brain regions [32]. Recent work suggests that the object perception, and finally the recognition of it, is associated with a kind of compromise between the way we think the object is and the "reality", of the way in which the object exists. This compromised functioning is involved in interactions between temporal and other inferior frontal regions of the brain [33]. A great deal of research has been devoted to documenting the perception of objects in youths with autism. The mounting evidence from such experiments has suggested that individuals with ASD retain but do not modify the origins of object perception easily.

\section{REAding PERCEPTUAL ABILITy}

A very basic and also important approach that has gained scientific respect in the last decade is the reading perceptual ability. The findings suggest that any language chosen activates specific regions of the human brain. As it is clear, the perceptual ability helps us to read. Thereby, we can distinguish between the lexical process and the comprehension process. However, many of the processes that make up the reading skill are negatively affected in dyslectic individuals. A multitude of computer tests have been developed to measure and improve the reading ability through memory processes. The former fall under the following categories:

1. Phonological awareness exercises. Two methods have been implemented for its measurement. The first are tests asking for the number of the various sounds heard when the individual reads semantically 
different words, and the second, tests where sounds have been removed from words and their correct reading is requested [34].

2. Phonological reading. To measure this ability in children, they are asked to read random words that are not part of a sentence. Some of these words are difficult and some are easy [35],[36].

3. Phonological coding. It includes the reminder of sounds from bead strings of letters which are sometimes in random order or sometimes these series contain parts of words [37],[38].

4. Lexical access: refers to the ability to recover words and their meaning from the long-term memory [39]. The question is how fast this can occur, and what is the period of time it requires?

In modern literature, dyslexia has been linked to memory, and in particular to working memory, receptive language and visual analysis. Therefore, any effort to decrease the negative effects of dyslexia incorporates the previous three aspects. There have also been several interventions, the most effective ones being the pedagogic ones [40],[41]. With respect to the aforementioned research in dyslexia, the difference in the time between stimulus and response in similar or dissimilar things, demonstrates the speed of the reaction time. In this sense, individuals with low abilities in verbal processes, such as dyslectic persons, require more time than individuals with high or normal verbal abilities.

\section{CONCLUSION}

The objective of this study has been to show if and how ICTs can assess people with perception problems and how this brain ability may be improved with the help of modern technology. With regard to special needs education, we have come to the conclusion that computers can cover and improve any weaknesses, such as filling in tests from a distance and the distinct time frames for their filling in.

In conclusion, we would also like to briefly summarize our goals for a possible subsequent research study :

- An additional mapping of high-level perceptual abilities, such as processes in which the stimuli are moving.

- The matching of the acoustic and visual perception in individuals with special needs, which is still at the initial stages.

- The finding of textbooks aimed at individuals with learning difficulties in reading, writing, reasoning ability and other abilities which are referred to as academic abilities or skills. Taking into consideration that learning difficulties frequently go hand in hand with other weaknesses, e.g. intellectual disabilities, emotional and neurological disorders, the more modern interventions try to correct the semantic, phonological and visual-perceptual problems.

Furthermore, starting from the main features of visual perception, we have provided a number of data directly related to an individual's cognitive condition, hoping that this information will help us to focus our further research on observation, as well as on training methods for individuals with special needs, with the help of ICTs. Lastly, we would like to express our view that the research areas of special education and perception and their correlation to ICTs calls for more research especially in the field of the intervention. However, we hope that the results of the current study are encouraging enough in order to reach the common general agreement that ICTs must play a significant role in the field of analyzing perception as an important brain process.

\section{REFERENCES}

[1] Jaeggi, S., Studer-Luethi, B., Buschkuehl, M., Yi-Fen, S., Jonides, J., Walter J, P.: The relationship between n-back performance and matrix reasoning implications for training and transfer. Intelligence 38(6), pp. 625-635, (2010) http://dx.doi.org/10.1016/j.intell. 2010.09.001

[2] Stephenson, C.L., Halpern, D.F., Improved matrix reasoning limited to training on tasks with a visuospatial component. Intelligence, 41(5), pp. 341-357, (2013) http://dx.doi.org/10.1016/ j.intell.2013.05.006

[3] Cutting, J.E.: Perception with an eye for motion. Cambridge. MA: MIT Press. (1986)

[4] Costall, A.: Beyond linear perspective: a cubist manifesto for visual science. Image Vision Computing 11(6), pp. 334-341, (1993) http://dx.doi.org/10.1016/0262-8856(93)90012-6

[5] Bruggeman, H., Yonas, A., Konczak, J.: The processing of linear perspective and binocular information for action and perception. $\begin{array}{llll}\text { Neuropsychologia, 45(7), pp. 1420-1426, (2007) } & \end{array}$ http://dx.doi.org/10.1016/j.neuropsychologia.2006.11.004

[6] Broerse J. et al.: The apparent shape of afterimages in the Ames room. Perception, 21(2), pp. 261-268, (1992) http://dx.doi.org/10.1068/p210261

[7] McIntosh, R.D., \& Lashley, G.: Matching boxes: familiar size influences action programming. Neuropsychologia, 46(9),pp. 2441-2444, (2008) http://dx.doi.org/10.1016/j.neuropsychologia. 2008.03.003

[8] Fajen, B.R., Jonathan. S.M.: Visual and Non-Visual Contributions to the Perception of Object Motion during Self-Motion. PLoS ONE, 8 (2), pp. 1-22, (2013) http://dx.doi.org/10.1371/ journal.pone.0055446

[9] Wexler, M., Panerai, F., Lamouret, I., Droulez, J.: Self-motion and the perception of stationary objects. Nature 409(6816),pp. 8588, (2001) http://dx.doi.org/10.1038/35051081

[10] Fernandez, J.M., \& Farell, B.: A neural model for the integration of stereopsis and motion parallax in structure from motion. Neurocomputing 71(7-9), pp: 1629-1641, (2008) http://dx.doi.org/10.1016/j.neucom.2007.04.006

[11] Hsu, L.C., Kramer, P., Yeh, S.L.: Monocular depth effects on perceptual fading. Vision Research, 50 (17), pp. 1649-1655, (2010) http://dx.doi.org/10.1016/j.visres.2010.05.008

[12] Grossberg, S., Swaminathan, G.: A laminar cortical model for 3D perception of slanted and curved surfaces and of 2D images: development, attention, and bistability. Vision research, 44(11), pp, 1147-1187, (2004)

[13] Zhang, J., Braunstein, M., Andersen, G.J.: Changes in angular size and speed affect the judged height of objects moving over a ground surface. Perception, 42(1), pp, 34-44, (2013)

[14] Blakeslee, B., McCourt, M.E.: A multiscale spatial filtering account of the White effect, simultaneous brightness contrast and grating induction. Vision Research, 39(26), pp, 4361-77, (1999)

[15] Faisman, A., Michael S.L.: How does lighting direction affect shape perception of glossy and matte surfaces? School of Computer Science In proceedings of the ACM Symposium on Applied Perception, pages 9-14, (2013) http://dx.doi.org/10.1145/ 2492494.2492502

[16] Scharstein, D., Szeliski, D.: High-Accuracy Stereo Depth Maps Using Structured Light. IEEE Computer Society, pages 195-202 (2003) http://dx.doi.org/10.1109/cvpr.2003.1211354

[17] Grove, P.M., Byrne, Barbara, J.M.: How configurations of binocular disparity determine whether stereoscopic slant or stereoscopic occlusion is seen. Perception, 34(9), pp, 1083-1094, (2005)

[18] Mather G.: The use of image blur as a depth cue. Perception, 26(9):1147-1158, (1997) http://dx.doi.org/10.1068/p261147

[19] Kemeny, A. and Panerai, F.: Evaluating perception in driving simulation experiments. TRENDS in Cognitive Science, 7(1), pp, 31-37, (2003) 
[20] Salmela, R. and Vanni, S.: Brightness and transparency in the early visual cortex. Journal of Vision, 13(7):16, pp, 1-14, (2013)

[21] Gori, S., Ronconi, L., Abalti, F., Molteni, M., Agostini, T. and Facoetti, A.: Brightness local bias in children with autism spectrum disorder. Journal of Vision, 12(9):793, pp, 1-15, (2012)

[22] Floyd, R.A., Dain, S.J. and Elliott R.T.: Is the perception of brightness different in poor readers? Vision Research 44 (2), pp, 221-227, (2004)

[23] Gegenfurtner, K.R., Rieger J.: Sensory and cognitive contributions of color to the recognition of natural scenes. Current Biology, 10(13), pp, 805-808, (2000)

[24] Russell, R., Sinha, P., Real-world face recognition: the importance of surface reflectance properties. Perception, 36(9), pp, 1368 1374, (2007)

[25] Allison, T., Ginter, H., McCarthy, G., Nobre, A.C., Puce, A. and Belger, A.: Face Recognition in Human Extrastriate Cortex. Journal of Neurophysiology, 71(2), pp, 821-825, (1994)

[26] Franklin, A., Sowden, P., Burley, R., Notman, L., Alder, E.: Color perception in children with autism. Journal of Autism and Developmental Disorders, 38(10), pp,1837-1847, (2008)

[27] Faccioli, C., Peru, A., Rubini, E., Tassinari, G.: Poor readers but compelled to read: Stroop effects in developmental dyslexia. Child Neuropsychology 14(3), pp, 277-283, (2008)

[28] Rello, L. and Baeza-Yates R.: Optimal Colors to Improve Readability for people with Dyslexia, Text Customization for Readability, Online Symposium.(2012) (link)

[29] Gilbert, C.D. and Sigman, M.: Brain states: top-down influences in sensory processing. Neuron 54(5), pp, 677-696, (2007)

[30] Corbetta, M., Shulman G.L.: Control of goal-directed and stimulus-driven attention in the brain. Nature Reviews Neuroscience, 3(3), pp, 201-215, (2002)

[31] Bertone, A., Mottron, L., Jelenic P. and Faubert, J.: Enhanced and diminished visuo-spatial information processing in autism depends on stimulus complexity. 128(10), pp, 2430-2441, (2005)

[32] Tyler L.K., Moss H.E.: Towards a distributed account of conceptual knowledge. Trends in Cognitive Sciences, 5(6), pp, 244-252 (2001)

[33] Clarke, A., Taylor, K.I., Tyler, L.K.: The evolution of meaning: spatiotemporal dynamics of visual object recognition. Journal of cognitive Neuroscience 23(8), pp, 1887-1899, (2011)

[34] Kazakou, M., Soulis, S., Morfidi, E., Mikropoulos, T.A.: Phonological Awareness Software for Dyslexic Children Themes in Science \& Technology Education, 4(1), pp, 33-51 (2011)

[35] Grammenou, A.: Dyslexics' Profile on the Working Memory Test Battery for Children, Phoneme Awareness and Literacy Measurements. International Conference on Social Science and Humanity, 5(1), pp, 227-232, (2011)

[36] Macoir, J., Fossard, M., Saint-Pierre M.C., Auclair-Ouellet N.: Phonological or procedural dyslexia: Specific deficit of complex grapheme-to-phoneme conversion. Journal of Neurolinguistics, 25(3), pp, 163-177, (2012)
[37] Nikolopoulos, D., Goulandris, N., Hulme, C., Snowling, M.J.: The cognitive bases of learning to read and spell in Greek: Evidence from a longitudinal study. Journal of Experimental Child Psychology, 94(1), pp, 1-17 (2006)

[38] Tamayo. F., Casals-Coll, M., Sánchez-Benavides, G., Quintana, M., Manero, R.M., Rognoni T., Calvo, L., Palomo, R., Aranciva, F., Peña-Casanova, J.: Spanish normative studies in a young adult population (NEURONORMA young adults project): Guidelines for the span verbal, span visuo-spatial, Letter-Number Sequencing, Trail Making Test and Symbol Digit Modalities Test. Neurología, (English Edition), 27(6), pp, 319-329, (2012).

[39] Douklias, S.D., Masterson, J., Hanley, J.R.: Surface and phonological developmental dyslexia in Greek. Cognitive Neuropsychology, 26(8), pp,705-23, (2009)

[40] Rello, L.: Design of Word Exercises for Children with Dyslexia Procedia Computer Science, 5th International Conference on Software Development and Technologies for Enhancing Accessibility and Fighting Info-exclusion, 27 ,74-83, (2014) http://dx.doi.org/10.1016/j.procs.2014.02.010

[41] Stienen-Durand, S., George J.: Supporting Dyslexia in the Programming Classroom. Procedia Computer Science, 5th International Conference on Software Development and Technologies for Enhancing Accessibility and Fighting Info-exclusion, (27), pp, 419-430, (2014) http://dx.doi.org/10.1016/j.procs.2014.02.046

\section{AUTHORS}

Athanasios Drigas is a Senior Researcher at IIT, N.C.S.R. Demokritos. He is the Coordinator of Telecoms $\mathrm{Lab}$ and founder of Net Media Lab since 1996. From 1985 to 1999 he was the Operational manager of the Greek Academic network. He has been the Coordinator of Several International Projects, in the fields of ICTs, and eservices (e-learning, e-psychology, e-government, einclusion, e-culture etc). He has published more than 260 articles, 7 books, 25 educational CD-ROMs and several patents. He has been a member of several International committees for the design and coordination of Network and ICT activities and of international conferences and journals. He has also received several distinctions for his scientific work (articles, projects, patents) (e-mail: dr@iit.demokritos.gr).

Diatsigkos Dimitris is a Chemist in Secondary Education. Since 2010 he is a Special Education Teacher. His students have learning disabilities ranging from autism and attention deficit disorder, to visual impairments and emotional disturbances (e-mail: ddiatsig@yahoo.gr).

Submitted 08 July 2014. Published as resubmitted by the authors 25 June 2015. 